\title{
Clinical comparison of elastic supports for venous diseases of the lower limb
}

\author{
D. B. GANDHI \\ F.R.C.S.
}

\author{
B. LEWIS \\ M.B.B.S.
}

J. R. PALMAR

F.R.C.S.

\author{
I. G. SCHRAIBMAN \\ M.Ch., F.R.C.S.(Edin), F.R.C.S.
}

Birch Hill Hospital, Rochdale, Lancs OL12 9QB

\section{Summary}

Compression garments for the lower limb were tested in two groups-general support garments and antiembolism supports. A total of 98 patients was examined. The method used was by the interposition of partly fluid-filled pressure sensors between garment and skin. A combination of roller bandage with shaped tubigrip (SBB-Seton) and Sigvaris stockings afforded effective pressure in the general support group but only the roller bandage plus pressure garment (Seton) did so in the anti-embolism group, both in the acute and prolonged studies.

KEY WORDS; varicose veins, gravitational disease, venous thrombosis prophylaxis, pulmonary embolism.

\section{Introduction}

The present study was undertaken to assess the effectiveness of some commonly used elastic supports for the lower limb. In order to predict whether a garment will be effective, some form of measurement must be made either static on a former or model by some mechanical device (favoured by manufacturers) or using the human leg, preferably (as in the present series) one which is suffering from the condition for which the support is required. The pressure at any point on a limb should clearly not exceed $30 \mathrm{mmHg}$ as this will tend to occlude arterial supply. Short of this it would seem reasonable to apply as much pressure as possible in a graded fashion from ankle decreasing through calf to thigh. These principles apply to both general support garments and anti-embolism stockings though from the technical point of view the measurement point is different depending on the clinical emphasis; in the former the critical point is above the medial malleolus where venous ulcers occur and in the latter it will be over the calf where most deep vein thromboses begin.
As manufacturers and clinicians are to some extent talking different languages in relation to elastic supports for the lower limb (as is evidenced by the fact that a British Standards Committee on this subject has failed to produce uniformity after may years of deliberation), this study was designed to help clinicians make an informed choice of garment and also to stimulate interest in the proper fitting of all garments in clinical situations.

\section{General support garments}

\section{Method}

Pressure exerted by the garments was transmitted by polythene bags partly filled with water interposed between garment and leg and relayed via a transducer to a digital voltmeter reading in $\mathrm{mmHg}$. Two $3 \mathrm{~cm} \times 3 \mathrm{~cm}$ bags each containing $1 \mathrm{ml}$ water were lightly taped to the skin proximal to medial and lateral malleoli and a $10 \mathrm{~cm} \times 10 \mathrm{~cm}$ bag containing $10 \mathrm{ml}$ water similarly applied over the prominence of the calf muscles. All four garments (see appendix) were applied in succession to one leg in random order and one measurement made for each with the patient standing.

\section{Subjects}

Forty patients with varicose veins prior to treatment and 12 patients with clinical gravitational disease were studied.

\section{Results}

The Seton combination (Elset bandage + SSB) and the Sigvaris stocking produced almost identical pressures of $26 \mathrm{~mm}$ at the lateral malleolus, $21 \mathrm{~mm}$ at the medial malleolus and $15-16 \mathrm{~mm}$ over the calf 
TABLE 1. Mean pressures and s.d. (mmHg) produced by four support garments in 40 patients with varicose veins in the standing position

\begin{tabular}{|c|c|c|c|c|c|c|}
\hline & Compressana (1) & STD (2) & Sigvaris (3) & Elset + SSB (4) & $P(1):(4)$ & $P(1):(3)$ \\
\hline $\begin{array}{l}\text { Calf } \\
\text { Medial malleolus } \\
\text { Lateral malleolus }\end{array}$ & $\begin{array}{r}6 \cdot 3 \pm 4 \cdot 3 \\
7 \cdot 9 \pm 4 \cdot 3 \\
10 \cdot 0 \pm 5 \cdot 2\end{array}$ & $\begin{array}{r}10 \pm 3 \cdot 1 \\
7 \pm 2 \cdot 6 \\
8 \pm 2 \cdot 7\end{array}$ & $\begin{array}{l}15 \pm 6 \cdot 1 \\
21 \pm 7 \cdot 8 \\
26 \pm 7 \cdot 5\end{array}$ & $\begin{array}{l}16 \cdot 7 \pm 6 \cdot 4 \\
21 \cdot 3 \pm 7 \cdot 7 \\
26 \cdot 4 \pm 7 \cdot 8\end{array}$ & $\begin{array}{l}<0.0005 \\
<0.0005 \\
<0.0005\end{array}$ & $\begin{array}{l}<0.0001 \\
<0.0005 \\
<0.005\end{array}$ \\
\hline
\end{tabular}

(1):(2) and (3):(4) not significant (Student's $t$-test).

TABLE 2. Mean pressures + s.d. (mmHg) produced by four anti-embolism support garments on legs of 20 subjects (single measurement)

\begin{tabular}{|c|c|c|c|c|c|c|}
\hline & TED (1) & Thrombo (2) & Struva (3) & Elset \& P.G. & $P(1):(4)$ & $P(1):(3)$ \\
\hline Ankle & $6 \cdot 5 \pm 84 \cdot 1$ & $11 \cdot 5 \pm 4.9$ & $11 \cdot 2 \pm 5 \cdot 4$ & $30 \cdot 1 \pm 9 \cdot 4$ & $<0.0005$ & $<0.0001$ \\
\hline Calf & $10 \cdot 1 \pm 5 \cdot 2$ & $6 \cdot 8 \pm 3 \cdot 1$ & $11 \cdot 7 \pm 4 \cdot 8$ & $24 \cdot 1 \pm 8 \cdot 9$ & $<0.0005$ & NS \\
\hline Thigh & $4.8 \pm 3.4$ & $3.4 \pm 1.9$ & $5 \cdot 7 \pm 2 \cdot 8$ & $13 \cdot 8 \pm 6 \cdot 2$ & $<0.0005$ & NS \\
\hline $\begin{array}{l}\text { Reversed } \\
\text { pressure } \\
\text { gradient }\end{array}$ & $16 / 20$ & $3 / 20$ & $11 / 20$ & $2 / 20$ & - & - \\
\hline
\end{tabular}

(1):(2) and (2):(3) not significant (Student's $t$-test).

(Table 1). Compressana and STD were again similar but with far lower pressures. The results in patients with gravitational disease were similar and are not separately shown.

\section{Anti-embolism garments: acute study}

\section{Method}

The same principle of measurement was used except that three of the $10 \mathrm{~cm} \times 10 \mathrm{~cm}$ bags were applied over the front of the ankle, bulk of the calf muscles and front of the thigh, $10 \mathrm{~cm}$ proximal to the upper border of the patella. All four garments (see appendix) were applied in random order to one limb and a single measurement made for each garment. The subjects were supine with the leg elevated to just above heart level.

\section{Subjects}

Twenty patients awaiting general surgical operations were examined.

\section{Results}

The Elset pressure garment (PG) combination produced pressures of about $30 \mathrm{~mm}, 24 \mathrm{~mm}$ and 14 $\mathrm{mm}$ at ankle, calf and thigh respectively (Table 2 ). A reversed pressure gradient (defined as a higher pressure at a proximal compared to a distal level) was present in over half the results with TED and Struva stockings but only in $3 / 20$ with Thrombo and $2 / 20$ with Elset + PG.

\section{Anti-embolism garments: prolonged study}

\section{Method}

The same method was used as in the acute stud except that three-way taps were swaged on to the tubing from the pressure sensors so that these could be disconnected without fluid leakage and with8uro disturbing the position of sensors or garmets. Garments (see appendix) were applied the day be operation and pressures measured. No measurem were made on the day of operation but pressures were recorded on four subsequent days, making five readings in completed cases of pressures at ankle, ca and thigh on both sides. Records were rejectef because of bag leakage in two cases and patient discomfort in three cases. Thus, 21 records wero available for analysis but in three these were incomê plete- two patients requested removal on the third post-operative day and one patient died after the fourth measurement.

\section{Subjects}

Twenty-six patients undergoing major genera्d surgical operations were studied.

\section{Results}

The pressures produced by the Seton combination (Elset bandage + PG) are compared with the Kenda TED + crepe bandage combination for the ankle, cale and thigh respectively (Table 3 ). In all three position and at all times, the pressures of the Kendall-crepe combination were significantly lower than those of the Seton garments except in the preoperative cal value. In both there was a loss of pressure over thछ 
TABLE 3. Mean pressures \pm s.d. ( $\mathrm{mmHg}$ ) produced at thigh, calf and ankle by two combinations of pressure garments in 21 subjects

\begin{tabular}{|c|c|c|c|c|c|c|}
\hline & \multicolumn{3}{|c|}{ Kendall-crepe } & \multicolumn{3}{|c|}{ Elset-P.G. } \\
\hline & Thigh & Calf & Ankle & Thigh & Calf & Ankle \\
\hline $\begin{array}{l}\text { Pre-operative } \\
\text { Post-operative }\end{array}$ & $9 \cdot 6 \pm 4 \cdot 6$ & $18 \cdot 5 \pm 4 \cdot 6^{*}$ & $22 \cdot 3 \pm 5 \cdot 2$ & $14 \cdot 1 \pm 5 \cdot 8$ & $21 \cdot 0 \pm 5 \cdot 6^{*}$ & $31 \cdot 0 \pm 7 \cdot 1$ \\
\hline $\begin{array}{l}\text { Day } 1 \\
\text { Day } 2 \\
\text { Day } 3 \\
\text { Day } 4\end{array}$ & $\begin{array}{l}4 \cdot 3 \pm 2 \cdot 9 \\
5 \cdot 1 \pm 2 \cdot 3 \\
4 \cdot 3 \pm 2 \cdot 3 \\
3 \cdot 6 \pm 2 \cdot 0\end{array}$ & $\begin{array}{r}11 \cdot 8 \pm 5 \cdot 2 \\
11 \cdot 3 \pm 3 \cdot 0 \\
10 \cdot 2 \pm 3 \cdot 4 \\
9 \cdot 3 \pm 2 \cdot 3\end{array}$ & $\begin{array}{r}14 \cdot 7 \pm 6 \cdot 2 \\
12 \cdot 0 \pm 4 \cdot 8 \\
10 \cdot 3 \pm 1 \cdot 1 \\
9 \cdot 1 \pm 3 \cdot 1\end{array}$ & $\begin{array}{l}9 \cdot 7 \pm 4 \cdot 5 \\
9 \cdot 7 \pm 4 \cdot 1 \\
8 \cdot 8 \pm 4 \cdot 2 \\
8 \cdot 5 \pm 3 \cdot 8\end{array}$ & $\begin{array}{l}17 \cdot 3 \pm 3 \cdot 8 \\
17 \cdot 1 \pm 4 \cdot 3 \\
16 \cdot 1 \pm 4 \cdot 3 \\
15 \cdot 9 \pm 4 \cdot 3\end{array}$ & $\begin{array}{l}27 \cdot 8 \pm 4 \cdot 5 \\
25 \cdot 7 \pm 4 \cdot 3 \\
24 \cdot 5 \pm 5 \cdot 0 \\
22 \cdot 9 \pm 4 \cdot 1\end{array}$ \\
\hline $\begin{array}{l}\text { Loss of mean } \\
\text { pressure over } \\
\text { study period (\%) }\end{array}$ & 63 & 50 & 59 & 39 & 24 & 26 \\
\hline
\end{tabular}

All mean pressures, Kendall T.E.D. v. Elset-P.G. differ significantly $(P<0 \cdot 0001$, Student's $t$-test $)$ except * $(P<0.065)$.

measurement period particularly between preoperative and first post-operative reading. The loss was relatively far greater with the TED-crepe support than with the Elset + PG.

\section{Discussion}

Pressure recorded is a resultant of at least three factors: (1) the basic stretch and regain characteristics of the material; (2) compliance of the 'material' lying under the sensor; (3) the Laplace relationship (pressure + tension/radius). Manufacturers' mechanical methods of measurement take account of factor (1) and should be cognisant of factor (3); only clinical measurement can incorporate the influence of all three factors.

When these measurements were made, the method used here (Fentem, Goddard and Gooden, 1976) was the only viable one for clinical use. Accepting that there is small error due to alteration of the circumference of the limb by the presence of the pressure bag, the results of this study are not invalidated as they are based on comparative rather than absolute values.

Siting of the pressure sensors was different for general support and anti-embolism garments. The critical position for the former is likely to be proximal to the medial malleolus where pressures are lower because of relative concavity (Laplace relationship) and where nutritional changes are found in gravitational disease. In anti-embolism studies, the calf is the most important situation because most clinically and isotopically detected thrombosis begins here. Thus a garment which cannot produce effective pressure in these situations should not be used, illustrating again the value of clinically orientated studies.

Anti-embolism garments have been shown to reduce significantly the incidence of isotopically diagnosed deep vein thrombosis (Allan et al., 1983), probably by decreasing leg vein transit time. Isotopic studies (Lawrence and Kakkar, 1980) have shown that the pressure developed is critical; too little pressure, defined as $<20 \mathrm{~mm}$ at the ankle, will be ineffective, but too much, $>30 \mathrm{~mm}$ at the ankle, may begin to compress arterioles while not improving venous flow. Therefore the values shown in this study are important to allow the clinician to judge whether garment pressure falls within the effective range, as well as indicating comparative values.

Loss of garment pressure with continuous use has been shown to apply to crepe bandages (Raj, Goddard and Makin, 1976), but as these are known to be clinically ineffective, such a result was predictable. The 6-day trial of anti-embolism supports was designed to this end. The Elset/pressure garment combination was the only one of the four antiembolism supports which provided effective graded pressure in acute and prolonged studies. Part of its effectiveness in the long-term studies may be due to the provision of a waistband which will minimise slippage down the limb with loss of pressure.

Manufacturers' claims of high pressures produced by garments cannot be accepted until the method of measurement is known. Only certain methods are applicable to clinical situations and these may imply some small degree of inaccuracy. This must be accepted for it is far out-weighed by the advantages of reproducing the clinical conditions of useon a human leg preferably in a patient suffering from the condition which the garment was designed to treat.

\section{Acknowledgments}

We would like to thank Dr M. Palmer of Christie Hospital for the statistics in Table 3. 


\section{Appendix}

\section{Garments used}

All garments were purchased through normal commercial channels and were fitted in accordance with manufacturers instructions.

\begin{tabular}{|c|c|c|}
\hline General support & & 1984 retail prices \\
\hline garments & & (not incl. $V A T)$ \\
\hline Compressana (Elbeo) & & $\mathfrak{£ 7 . 4 3}$ \\
\hline STD & & $£ 6.63$ \\
\hline Sigvaris (Ganzoni) & & $£ 25.13$ \\
\hline Elset Bandage & $£ 1.60$ & \\
\hline + SSB (Seton) & $£ 3.15$ & \\
\hline Anti-embolism garments & (two legs) & \\
\hline TED (Kendall) & & $£ 19.62$ \\
\hline Sigvaris Thrombex & & \\
\hline (Ganzoni) & & $£ 12.72$ \\
\hline Struva (STD) & & $\begin{array}{l}\text { No price } \\
\text { available }\end{array}$ \\
\hline Elset Bandage $\times 2$ & $£ 3.20$ & \\
\hline $\begin{array}{l}\text { Double leg pressure } \\
\text { garment (Seton) }\end{array}$ & $£ 22.20$ & $£ 25.40$ \\
\hline
\end{tabular}

In the 6-day anti-embolism study, two garments were compared: Kendall TED over double layer of $15 \mathrm{~cm}$ crepe bandage and Seton pressure garmen (PG) over double layer of $15 \mathrm{~cm}$ Elset roller bandage Left and right legs were alternated so that in $1 \mathrm{~K}$. subjects the Seton garments were applied to the righ leg and in 10 to the left leg.

\section{References}

Allan, A., Williams, J.T., Bolton, J.P. \& Le Quesne, L.P. (1983 The use of graduated compression stockings in the prevention of post-operative deep vein thrombosis. British Journal of Surger 70, 172.

Fentem, P., Goddard, M. \& Gooden, B. (1976) Support for-ü varicose veins. British Medical Journal, 254, 1.

LAWRENCE, D. \& KAKKAR, V.V. (1980) Graduated static externat compression of the lower limb: a physiological assessment. Britis Journal of Surgery, 67, 119.

RaJ, T.B., Goddard, M. \& Makin, G.S. (1976) How long di் compression bandages maintain their pressure during ambulatorf treatment of varicose veins? British Journal of Surgery, 67, 122 .

(Accepted 21 September 1983) 